\title{
Brain Training Improves Cigarette Smoke Induced Dementia in Female C57 Black 6 Mice
}

\begin{abstract}
ANJALI RAJ, SADASHIVAIAH ${ }^{1}$, S. V. MADHUNAPATULA² AND MANJULA S. N*
Department of Pharmacology, JSS College of Pharmacy, JSS Academy of Higher Education and Research, Mysuru, Karnataka 570015, ${ }^{1}$ Department of Molecular Biology, Yuvaraja's College, University of Mysore, Mysuru 570005, ${ }^{2}$ Department of Biochemistry, Center of Excellence in Molecular Biology and Regenerative Medicine, JSS Medical College, JSS Academy of Higher Education and Research, Mysuru, Karnataka 570015, India
\end{abstract}

Raj et al.: Evaluation of Brain Training Effects on Cigarette Smoke Induced Dementia: An In vivo Study

\begin{abstract}
Alzheimer's disease is a chronic neurodegenerative disease among the elderly population. Various genetic, environmental and lifestyle factors have been associated with the etiology of Alzheimer's disease. Cigarette smoke has been reported to be a major predisposing factor for Alzheimer's disease and contributes to disease development. Conversely, studies have reported beneficial effects of brain training on the disease condition. The purpose of this study was to evaluate the effect of a brain training task in cigarette smoke induced dementia. Three groups of female C57 black 6 mice were used in the study with two of the groups subjected to cigarette smoke exposure. The third group was subjected to a novel object test immediately after the exposure. Brain training improved the cognitive domains of the smoke exposed mice. Brain training could also regain the neurotransmitter imbalances induced by cigarette smoke, importantly, decreased the glutamate levels in the hippocampus. Brain training also significantly decreased the hippocampal amyloid precursor protein expression levels by reducing the reactive oxygen species production. Additionally, the improved hippocampal neuronal count, post training supported the findings. The results indicated that brain training significantly decreased the deleterious effects of cigarette smoke in hippocampus tissue and improved dementia symptoms.
\end{abstract}

Key words: Dementia, Alzheimer's disease, cigarette smoke, brain training, hippocampus, amyloid beta

Dementia is an umbrella term used to represent a group of conditions characterized by impairments in cognitive modalities such as memory, judgement, language, problem solving capabilities, all of them affecting the daily life of an individual[ ${ }^{[1,2]}$. Alzheimer's disease (AD) is an irreversible progressive neurodegenerative disorder and most importantly the widest occurring form of dementia ${ }^{[3]}$. According to the 2015 World Alzheimer Report, the dementia sufferers approximated 36 million in number which is expected to double by $2030^{[4]}$. As per the 2018 report, AD emerged as the primary killer in England and Wales, the prevalence being higher among women ${ }^{[5]}$. This sudden alarming increase in the disease statistics could probably have a direct correlation with environmental, lifestyle and socioeconomic factors.

Cigarette smoke (CS) has been reported to be an important environmental toxin and burning of a single cigarette reportedly produced almost 4000 chemicals, most of which are found to be contributors to oxidative stress and accelerated aging ${ }^{[6]}$. CS is also

*Address for correspondence

E-mail: snm.manjula@gmail.com

May-June 2021 a major risk factor for AD. Scientific evidences have indicated to poor working and visuospatial memory in active smokers. Active smokers were also found to exhibit impaired mini mental state examination scores (MMSE) compared to their normal counterparts and the scores were found to lower with the increase in smoking duration $^{[7]}$. CS has also been reported for increased global atrophy in computed topography scans. Magnetic resonance imaging studies further demonstrated reduced gray matter volumes in the temporal and frontal brain regions of active smokers all indicating to neurodegenerative consequences ${ }^{[7,8]}$. Smoking is also found to be associated with decreased attention, planning capabilities and other cognitive functions in active and former smokers ${ }^{[7,9]}$. Despite all these

This is an open access article distributed under the terms of the Creative Commons Attribution-NonCommercial-ShareAlike 3.0 License, which allows others to remix, tweak, and build upon the work non-commercially, as long as the author is credited and the new creations are licensed under the identical terms 
reported deleterious effects, the exact mechanism of the CS induced neurocognitive effects is still unknown. An in vivo study on amyloid precursor protein (APP)/mutant presenilin 1 (PS1) transgenic mice indicated that CS exposure significantly exacerbated amyloid beta (A $\beta)$ depositions and resulted in tau phosphorylation, major histopathological hallmarks of $\mathrm{AD}$, in the hippocampus and cortex tissues of the animals ${ }^{[10]}$. However, a recent contradicting report suggested that CS might not have any effect on dementia development regardless of its reported detrimental activities ${ }^{[11]}$.

Cognitive stimulation is one of the most widely accepted non-pharmacological treatment method in mild to moderate dementia. The therapy involves stimulating the brain through number of mental exercises which are considered to increase the brain plasticity and restore the cognitive reserve ${ }^{[12]}$. Cognitive Stimulation Therapy (CST) has been found to be effective in improving MMSE scores of dementia patients, indicating to a betterment of overall cognition. The quality of life of the demented individuals was also reported to be enhanced and a sense of wellbeing was instilled ${ }^{[13]}$. Further, researchers have also reported a substantial benefit on mental activities in AD dementia. Mental stimulation was found to increase the cognitive reserve throughout life allowing memory functions to be maintained in the old age and thereby decreasing $\mathrm{AD}$ susceptibility ${ }^{[14]}$. Epidemiological studies on education levels and $\mathrm{AD}$ dementia supported these findings by suggesting that low education levels could also increase the risk for the disease development in late stages ${ }^{[14,15]}$.

Owing to these studies and reports, the present study was designed with the objective to assess the effect of a brain training task on CS exposed female black mice. Additionally, we also wanted to re-confirm the dementia effects of CS due to conflicts in reported studies. Female mice were used for the study due to the higher prevalence of $\mathrm{AD}$ among women, twice the rate compared to men. Moreover, World Health Organization (WHO) has reported an increase in the worldwide female smokers especially within the urban communities of developed countries, where gender inequality doesn't exist ${ }^{[16]}$. The number of women smokers was also proposed to increase significantly in the low-middle income countries, calling the need to study the effects of CS on females.

\section{MATERIALS AND METHODS}

All reagents and chemicals used in the study were of analytical grade. Cigarettes from a popular brand were purchased from a certified wholesale dealer. All major chemicals like 2',7'-dichlorofluorescein diacetate (CAS Number 4091-99-0), Cresyl violet stain (CAS Number: 10510-54-0), gamma amino butyric acid (GABA) (CAS Number: 56-12-2), serotonin (CAS Number 50-67-9) and L-glutamic acid standards (CAS Number 56-86-0 ) for neurotransmitter estimations were procured from Sigma-Aldrich. Ellman's reagent (CAT number: 22582) was procured from Thermo Fisher Scientific. Primary A $\beta$ antibody (STJ91591) was purchased from St. John's Laboratory and the secondary antibody (SC 2004) was procured from Santa Cruz biotechnology. The Cotinine enzyme-linked immunosorbent assay (ELISA) kit (CO096D-100) was purchased from Calbiotech.

\section{Animals:}

Female C57 black $6(\mathrm{C} 57 \mathrm{BL} / 6)$ mice weighing between 25-30 g and aged 2-3 mo old were procured from an approved Committee for the Purpose of Control and Supervision of Experiments on Animals (CPCSEA) breeder. Animals were given optimal time for acclimatization, housing and feeding were given according to the CPCSEA guidelines. All experiments were performed according to the ethical norms sanctioned by the Institutional animal ethics committee (IAEC).

\section{CS exposure:}

The inhalation setup was modified according to the laboratory conditions and consisted of fiberglass chambers; one each for normal and smoke exposed animals, connected to a peristaltic pump. The chambers were non-ventilated except for a small hole to hold the tube connecting to the pump. The peristaltic pump sucked in the generated smoke from the cigarette at a rate of $1 \mathrm{ml} / \mathrm{min}$ and delivered it into the chamber holding the animal. A cigarette holder was attached to one end of the pump. The entire setup was placed in a smoke hood to reduce smoke spreading in room. The study consisted of three different groups of animals: the control group (normal) of animals; not exposed to smoke, the smoking alone group served as the second group exposed to CS, the third group of animals (Smoking+T) were made to perform a memory exercise (novel object recognition test) daily, after exposure to smoke. This group studied the effect of brain training on smoking. The animals, immediately after smoke inhalation, were brain teased daily by exposing them to novel object recognition test. All animals were acclimatized with the chamber before smoke exposure. 
When the second and third groups of animals were exposed to CS, the normal group of animals was made to inhale room air under the same conditions.

The filter from a cigarette was removed and lighted within the holder to generate smoke for inhalation of the mice. The whole cigarette was allowed to burn, which took approximately 15-20 min. However, the animals were placed in the chamber for another $10 \mathrm{~min}$ and allowed to inhale the accumulated smoke in the chamber. The process was repeated for $5 \mathrm{~d} / \mathrm{w}^{[10]}$ over a period of 4 mo continuously. The chamber was cleaned off for any animal waste each time immediately after the exposure. The tubes were replaced every week to ensure uniformity in inhalation. The entire procedure was performed under controlled conditions. All care was taken that the experimenter was least affected by CS.

\section{Training of smoke exposed animals:}

For novel object recognition test, we did not subject the animals to a trail but trained them for familiarizing to an object and allowed them to explore novel objects. Each animal of the smoking $+\mathrm{T}$ group was placed in the center of the arena where it was left to explore the familiar objects for $10 \mathrm{~min}$. After a gap of $30 \mathrm{~min}$, the same animal was exposed to a novel object along with one of the familiar objects. Another $10 \mathrm{~min}$ was given to the animals to explore the novel object ${ }^{[17]}$. The process continued everyday immediately after smoke exposure for a period of 4 mo. No data was recorded.

\section{Cotinine estimation in blood:}

Cotinine, major metabolite of nicotine, has a longer half-life than its parent compound. Hence plasma cotinine levels serve as an indicator of proper tobacco exposure $^{[10]}$. Cotinine level was measured by using an ELISA kit procured from Calbiotech. Blood was collected into ethylenediamine tetraacetic acid (EDTA) coated tubes from animals through tail vein puncture on $1^{\text {st }}, 2^{\text {nd }}$ and $3^{\text {rd }} \mathrm{d}$ immediately after smoke exposure. Plasma was separated through centrifugation at $2000 \mathrm{~g}$ for $20 \mathrm{~min}$. Protein fractions were loaded onto ELISA plates and further treatment was done according to the manufacturer instructions. Absorbance was measured at $450 \mathrm{~nm}$ on an ELISA plate reader (Perkin Elmer).

\section{Behavioral parameters:}

T-maze and passive avoidance tests were performed for determining memory levels of the study animals, both indicative of working and retention memory respectively.

\section{T-maze test:}

A T-maze with three arms was fabricated according to standard dimensions. The stem of " $T$ " was built longer than the other arm. Left-right discrimination protocol was used to assess the working memory of the animals ${ }^{[18]}$. The mouse was allowed to run free trails in the acclimatization phase to determine its choice of arm. The preferred arm was then considered the goal arm (reward arm-arm in which the food pellet is placed). The mice underwent almost 10 acquisition trials/d, cut off time of $100 \mathrm{~s}$, until the animals learned to reach the reward arm. Endpoint was considered when the animal enters the arm and nibbles the food pellet. Animal traces were removed using $25 \%$ alcohol before placing a new animal in the maze. The animals were then tested by reversing the goal arm i.e. the reward arm is reversed to the previously un-baited arm. The time taken to reach the new reward arm was noted in seconds.

\section{Passive avoidance test:}

Step down latency test was used to measure the memory retention capacity of the animals. Inhibitory/passive avoidance test is usually performed using a step-down apparatus. A typical step-down apparatus consists of an illuminated box with a frontal sliding door of $0.1 \mathrm{~cm}$ steel grids which are almost $1 \mathrm{~cm}$ apart. The study was divided into the training and testing phase. In the training phase, mice were taught to remain on an elevated platform placed over the grids. Any animal stepping down was made to receive a foot shock of 0.2-1.0 milliAmpere (mA) for $3 \mathrm{~s}^{[19]}$. Proper precautions were taken to eliminate any form of animal traces (urine/faeces) using $25 \%$ diluted alcohol. In the test phase, the subjects were placed in the same apparatus and conditions without the delivery of a foot shock. Time taken by the animals to step down was noted. The cut-off time was set to $180 \mathrm{~s}$.

\section{Animal euthanasia and tissue collection:}

The animals were sacrificed immediately after 4 mo $(120 \mathrm{~d})$. The brains were excised and washed in phosphate buffer saline (PBS). The hippocampal tissues were separated and stored in $-80^{\circ}$ until further use. Whole brains for histopathological analysis were immediately placed in $10 \%$ formalin solution. 


\section{Western blot analysis for APP estimation:}

Tissue homogenates were prepared in cell lysis buffer (cell signaling) and subjected to centrifugation at 12000 $\mathrm{rpm}$. The supernatant was collected and used for protein quantification using Lowry's method. Equal amount of protein $(30$ to $40 \mu \mathrm{g})$ from different samples were loaded to $10 \%$ sodium dodecyl sulphate poly acrylamide gel (SDS-PAGE) electrophoresis. Proteins resolved in gel were transferred to nitrocellulose membrane. Blots were blocked with $5 \%$ non-fat dry milk powder for preventing non-specific antibody binding ${ }^{[20]}$. The blots were then incubated with the specific primary antibody (APP STJ91591) at $40^{\circ}$ overnight. Thereafter, Tris-buffered saline-Tween solution (TBST) was used to wash the blots three times for $15 \mathrm{~min}$ each to remove non-bound primary antibodies. Again, blots were treated with the secondary antibody (goat anti-rabbit IgG Horseradish peroxidase) for $1 \mathrm{~h}$ at room temperature. The washing process was repeated again; twice with TBST for $15 \mathrm{~min}$ each and once with TBS for another $15 \mathrm{~min}$ to remove unbound secondary antibodies and further treated with chemiluminescence reagent. The protein visualization process was performed using Syngene Gel Doc system coupled with blue light transilluminator. To validate uniform loading of protein, the blots were re-probed with housekeeping protein, actin. The images were quantified using densitometric analysis in image $\mathrm{J}$ software.

\section{Reactive oxygen species (ROS) analysis:}

2,7-Dichlorodihydrofluorescein-Diacetate

(DCFH$\mathrm{DA})$ reagent was used to measure the generation of intracellular ROS. DCFH-DA converts into fluorescent DCF upon reaction with ROS, forms the basic principal of this assay. The isolated mice hippocampal tissues were homogenized with $0.9 \%$ sodium chloride solution. This homogenized solution was centrifuged at $100 \mathrm{~g}$ for $10 \mathrm{~min}, 10^{\circ}$ and the supernatant was collected. $2 \mu 1$ of the supernatant was separated and $198 \mu 1$ PBS was added into it. Further, $100 \mu 1$ from the prepared solution and $100 \mu \mathrm{l}$ of DCFH-DA solution was added into a 96 well microplate. The ROS levels were detected at an excitation wavelength of $485 \mathrm{~nm}$ and an emission wavelength of $525 \mathrm{~nm}^{[21]}$ in a multimode microplate reader (Perkin Elmer).

\section{Neurotransmitter estimation:}

\section{Measurement of serotonin levels:}

Hippocampal tissues were homogenized with $0.9 \%$ perchloric acid and centrifuged at $10000 \mathrm{rpm}$ for
15 min. Resulting supernatant was collected and sieved through a $0.22 \mu \mathrm{m}$ filter for high performance liquid chromatography (HPLC) analysis. Mobile phase composed of $82.4 \%$ water, $17.6 \%$ methanol, 20 milli molar $(\mathrm{mM})$ of disodium hydrogen orthophosphate, $15 \mathrm{mM}$ of citric acid, $9 \mathrm{mM}$ DL10-camphor sulfonic acid, $1.512 \mathrm{mM}$ of triethylamine and $0.0876 \mathrm{mM}$ of EDTA with a flow rate of $0.7 \mathrm{ml} / \mathrm{min}^{[22]}$. HPLC system with an electrochemical detector (Model 1645, Waters, USA) and octadecylsilane (C18) column (Sphericob, reverse phase (RP) C18, $5 \mu \mathrm{m}$ particle size, $4.6 \mathrm{~mm}$ $\times 250 \mathrm{~mm}$ at $30^{\circ}$ ) was used for the analysis. Serotonin standard was injected separately. The concentration of neurotransmitters in samples were calculated by comparing with the peak area of standards and expressed in $\mathrm{ng} / \mathrm{mg}$ of wet tissue.

\section{Measurement of glutamate and GABA:}

Isolated hippocampal tissues were homogeniz in $500 \mu \mathrm{l}$ of deionized water and centrifuged at $10000 \mathrm{rpm}$ for $20 \mathrm{~min}$. Resulting supernatants were separated and filtered through $0.22 \mu \mathrm{m}$ filters. $10 \mu \mathrm{l}$ of the filtrate was added to $990 \mu \mathrm{l}$ of deionized water and diluted for HPLC analysis. Mobile phase comprised of $0.1 \mathrm{M}$ monosodium phosphate and $0.5 \mathrm{mM}$ EDTA dissolved in $23 \%$ methanol in distilled water. $\mathrm{pH}$ was adjusted using $1 \mathrm{M}$ phosphoric acid. The amino acids were derivatized by Ortho-Pthaldialdehyde (OPA)/ sodium sulphite solution in ethanol $(500 \mu \mathrm{l}$ of absolute ethanol, $500 \mu \mathrm{l}$ of $1 \mathrm{M}$ sodium sulphite and $900 \mu \mathrm{l}$ of $0.1 \mathrm{M}$ sodium tetraborate buffer $(10.4 \mathrm{pH}$ using $5 \mathrm{M}$ sodium hydroxide) was used to dissolve $22 \mathrm{mg}$ of OPA) [23]. HPLC system with an electrochemical detector (Model 1645, Waters, USA) and C18 column(Sphericob, RP C18, $5 \mu \mathrm{m}$ particle size, $4.6 \mathrm{~mm} \times 250 \mathrm{~mm}$ at $30^{\circ}$ ) was used for the analysis. Standard stock solutions of GABA and L-glutamic acid standards were injected separately. The concentration of neurotransmitters in samples were calculated by comparing with the peak area of standards and expressed in $\mu \mathrm{g} / \mathrm{mg}$ of wet tissue.

\section{Acetylcholinesterase (AChE) analysis:}

AChE levels in the hippocampal regions were measured separately using Ellman's assay. The tissues were homogenized in $0.03 \mathrm{M}$ sodium phosphate buffer $(\mathrm{pH} 7.4)$ to produce $10 \% \mathrm{w} / \mathrm{v}$ homogenates and aliquoted. The protein levels in homogenates were determined by Bradford assay.

$0.4 \mathrm{ml}$ aliquots was added to $2.6 \mathrm{ml}$ phosphate buffer $(0.1 \mathrm{M}, \mathrm{pH} 8)$ and $100 \mu \mathrm{l}$ of 5,5'-Dithiobis 
(2-nitrobenzoic acid) (Ellman's reagent) in a cuvette. The absorbance was measured at $412 \mathrm{~nm}$ using an ultraviolet (UV) visible spectrophotometer (Shimadzu, Japan ${ }^{[24]}$. This was recorded as the basal reading. $20 \mu 1$ of acetylthiocholine iodide was then added to initiate the reaction and absorbance was recorded at every $30 \mathrm{~s}$ intervals for $10 \mathrm{~min}$. AChE levels were expressed in $\mu \mathrm{mol} / \mathrm{min} / \mathrm{mg}$.

\section{Cresyl violet staining:}

The formalin fixed samples were cut into coronal sections of 3-5 $\mu \mathrm{m}$. Sections were then deparaffinised with 2 xylene washes and hydrated with descending grades of alcohol and distilled water. $0.1 \%$ cresyl violet solution was used for staining the sections (3-10 $\mathrm{min}$ ), thereafter, quickly rinsed with distilled water. The sections were differentiated in $95 \%$ ethyl alcohol for 2-10 min and dehydrated using absolute alcohol. Permanent mounting medium was used to mount the slides and observed for Nissl's granules ${ }^{[25]}$. Neuronal count was measured using Olympus magvision software (calibrated with $\mu \mathrm{m}$ ). All sections were captured at 40x magnification and subjected for counting (number of neurons $/ 100 \mu \mathrm{m}$ section). The histopathological examination and corresponding scoring were performed by a trained veterinarian.

\section{Statistical analysis:}

Statistical analysis was performed using GraphPad Prism (version 6.0 software). Analysis of variance (ANOVA) was used for comparison followed by appropriate post hoc tests (Tukey's/Bonferroni's), $\mathrm{p} \leq 0.05$ was considered as statistically significant.

\section{RESULTS AND DISCUSSION}

Cotinine levels were estimated to confirm the proper intake of smoke by the animals. Cotinine possesses a longer half-life than nicotine and its plasma concentration is found to be less affected by the blood sampling time, making the metabolite easily detectable than the parent compound ${ }^{[26]}$, hence can be measured in plasma. The cotinine levels after $1^{\text {st }}$, $2^{\text {nd }}$ and $3^{\text {rd }} \mathrm{d}$ of CS exposure was determined using ELISA method. Cotinine levels can vary from $10 \mathrm{ng} /$ $\mathrm{ml}$ in a light active smoker to $500 \mathrm{ng} / \mathrm{ml}$ in a heavy smoker ${ }^{[10]}$. Both the smoke exposed groups significantly increased the cotinine levels from $3.56 \pm 0.57$ to 10.65 $\pm 0.97 \mathrm{ng} / \mathrm{ml}$ and $3.49 \pm 0.45$ to $10.67 \pm 0.86 \mathrm{ng} / \mathrm{ml}$ respectively as represented in Table 1 , indicating that the animals of both groups received smoke comparable to a light active smoker.

Working memory was measured in animals by T-maze. Left-right discrimination protocol was used to assess the working memory in smoke exposed mice. The memory assessment was performed every $4 \mathrm{w}$ of smoke inhalation for four consecutive months. The normal group of animals did not exhibit any changes in the time taken to reach the reward arm even after its reversal. The normal animals took $10.66 \pm 2.20 \mathrm{~s}$ in the $1^{\text {st }} \mathrm{W}$ while they took $6.66 \pm 2.11 \mathrm{~s}$ to find the reversed arm in the $16^{\text {th }}$ $\mathrm{w}$ assessment as represented in Table 2. The smoking alone group of animals took significantly increased time to find the reversed arm compared to normal groups. Animals took $20.50 \pm 4.20 \mathrm{~s}$ in the $1^{\text {st }} \mathrm{W}$ assessment while took $100.00 \pm 4.10 \mathrm{~s}$ in the $16^{\text {th }} \mathrm{W}$ assessment of the task. The trained group of animals also significantly increased the latency time compared to normal groups. The animals took $13.67 \pm 3.90 \mathrm{~s}$ to find the reversed arm in the $1^{\text {st }} \mathrm{W}$ assessment while took $55.67 \pm 3.75 \mathrm{~s}$ in the $16^{\text {th }} \mathrm{W}$ assessment (Table 2). However, training of the smoke exposed group significantly decreased the latency time of animals in the $16^{\text {th }} \mathrm{W}$ compared to the smoking alone group indicating to a beneficial effect of continuous brain teasing on the smoke exposed animals.

TABLE 1: EFFECT OF CS EXPOSURE AND BRAIN TRAINING ON COTININE LEVELS IN BLACK MICE

\begin{tabular}{|c|c|c|c|}
\hline \multirow{2}{*}{ Groups } & \multicolumn{3}{|c|}{ Cotinine levels (ng/ml) } \\
\hline & $1^{\text {st }} d$ & $2^{\text {nd }} d$ & $3^{\text {rd }} d$ \\
\hline $\begin{array}{l}\text { Smoking } \\
\text { alone }\end{array}$ & $3.56 \pm 0.57$ & $8.45 \pm 0.85^{* *}$ & $10.65 \pm 0.97^{* *}$ \\
\hline Smoking $+\mathrm{T}$ & $3.49 \pm 0.45$ & $8.52 \pm 0.80^{\# \#}$ & $10.67 \pm 0.86^{\# \#}$ \\
\hline
\end{tabular}

All values are expressed as mean \pm standard error of mean (SEM), $\mathrm{n}=4$. Data was analyzed by two-way ANOVA followed by post hoc Bonferroni multiple comparison test. " $p<0.01$ compared to $1^{\text {st }} d$ of smoking alone group and ${ }^{\# \#} p<0.01$ compared to $1^{\text {st }} d$ of smoking $+T$ group

TABLE 2: EFFECT OF CHRONIC SMOKE EXPOSURE AND SUBSEQUENT BRAIN TRAINING ON T-MAZE TASK

\begin{tabular}{|c|c|c|c|c|}
\hline \multirow{2}{*}{ Groups } & \multicolumn{4}{|c|}{ Time taken to reach reward arm (s) } \\
\hline & $1 \mathrm{w}$ & $4 \mathrm{w}$ & $8 w$ & $16 \mathrm{w}$ \\
\hline Normal & $10.66 \pm 2.20$ & $12.50 \pm 2.13$ & $8.50 \pm 1.90$ & $6.66 \pm 2.11$ \\
\hline Smoking alone & $20.50 \pm 4.20$ & $57.66 \pm 3.23^{* * *}$ & $87.50 \pm 4.20^{* * *}$ & 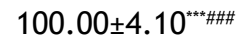 \\
\hline Smoking $+\mathrm{T}$ & $13.67 \pm 3.90$ & $60.67 \pm 4.20^{* * *}$ & $71.66 \pm 3.80^{* * *}$ & 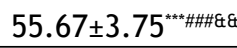 \\
\hline
\end{tabular}

All values are expressed as mean $\pm S E M, n=6$. Data was analyzed by two-way ANOVA followed by post-hoc Bonferroni multiple comparison test. " $\mathrm{p}<0.5, " \mathrm{p}<0.01$ and ${ }^{\prime \prime \prime} \mathrm{p}<0.001$ compared to the respective normal groups. ${ }^{\# \#} \mathrm{p}<0.001$ compared to $1^{\text {st }} \mathrm{W}$ of respective smoking groups (smoking alone and Smoking+T). ${ }^{\text {\&4t }} \mathrm{p}<0.01$ compared to respective smoking alone group 
Step down latency was used to gauge the memory retention of the animals. Step down latency is a paradigm to test the passive avoidance behavior of animals. The time a mouse takes to step down from a raised surface was noted, $180 \mathrm{~s}$ being the cut off. CS exposure significantly decreased the time taken to step down. The step down latency of smoking alone group decreased from $163.66 \pm 5.61 \mathrm{~s}$ in $1^{\text {st }} \mathrm{W}$ assessment to $20.66 \pm 2.87 \mathrm{~s}$ in $16^{\text {th }} \mathrm{W}$ compared to the respective normal groups $(180.00 \pm 4.8333$ vs. 180.00 \pm 5.20 s). The Smoking+T group of animals also exhibited a significantly decreased step down latency from $1^{\text {st }} \mathrm{W}$ to $16^{\text {th }} \mathrm{W}$ compared to the normal group $\left(160.50 \pm 5.57\right.$ vs. $180.00 \pm 4.83\left(1^{\text {st }} \mathrm{w}\right), 65.50$ \pm 3.90 vs. $180.00 \pm 5.20\left(16^{\text {th }} \mathrm{w}\right)$ as represented in Table 3. Nevertheless, the trained group of animals exhibited better memory retention compared to the smoking alone group. The animals not only took increased time to step down on to the grid but also appeared to be more careful than the smoking alone group of animals.

APP is a cell surface protein which is cleaved by secretases to form toxic $A \beta$ fragments $\left(A \beta_{1-40}\right.$ and $A \beta_{1-42}$ fragments) through amyloidogenic pathway ${ }^{[27]}$. Blots obtained from western blotting studies on hippocampal tissue of normal and smoke exposed groups are represented in fig. 1. The APP levels of smoking alone $(1.035 \pm 0.132)$ significantly increased in the hippocampus tissue in comparison to normal group $(0.186 \pm 0.0621)$ as indicated in Table 4 and significantly increased hippocampal APP level compared to the normal hippocampus $(0.186 \pm 0.0621)$. No significant difference was exhibited between the trained group $(0.371 \pm 0.0763)$ and the normal group of animals. However, Smoking+T group exhibited significantly lower levels of hippocampal APP expression compared to the smoking alone group (Table 3), probably one of the reasons for enhanced cognitive behaviour of the smoke exposed mice post training.

ROS is a major culprit in induction of oxidative stress. The relative fluorescence intensity of hippocampal tissues was measured using DCFH-DA assay. CS exposure was found to increase the ROS levels in the tissue. The normal hippocampal tissue expressed ROS level of $62.34 \pm 5.66$. The Relative fluorescence intensity of smoking alone and smoking $+\mathrm{T}$ group were measured as $151.34 \pm 6.70$ and $124.55 \pm 7.80$ respectively as indicated in Table 5. Again, the trained group of animals significantly decreased the fluorescent intensity compared to smoking alone group in the hippocampal tissue. Decreased ROS is long associated to $A \beta$ cascade including its generation from APP.

Serotonin is the major neurotransmitter responsible for mood regulations. Additionally, serotonin is also reported to improve memory functions ${ }^{[28]}$. HPLC method coupled with Electrochemical (EC) detection was performed for the neurotransmitter estimation. Normal serotonin levels in the hippocampus were estimated to be $0.611 \pm 0.045 \mathrm{ng} / \mathrm{mg}$ of wet tissue. The smoking alone group significantly increased the hippocampal $(0.923 \pm 0.068 \mathrm{ng} / \mathrm{mg}$ of wet tissue $)$ serotonin levels compared to the normal group as

TABLE 3: EFFECT OF BRAIN TRAINING ON CS EXPOSED MICE IN STEP DOWN LATENCY TASK

\begin{tabular}{lcccc}
\hline \multirow{2}{*}{ Groups } & \multicolumn{4}{c}{ Step down latency (s) } \\
\cline { 2 - 5 } & $1 \mathrm{w}$ & $\mathbf{4}$ & $\mathbf{8} \mathrm{w}$ & $16 \mathrm{w}$ \\
\hline Normal & $180.00 \pm 4.83$ & $180.00 \pm 5.10$ & $176.50 \pm 4.35$ & $180.00 \pm 5.20$ \\
Smoking alone & $163.66 \pm 5.61^{* * *}$ & $75.50 \pm 3.67^{* * *}$ & $31.67 \pm 2.51^{* * *}$ & $20.66 \pm 2.87^{* * * \# \#}$ \\
Smoking+T & $160.50 \pm 5.57^{*}$ & $70.66 \pm 4.33^{* * *}$ & $60.50 \pm 4.67^{* * * \varepsilon \varepsilon}$ & $65.50 \pm 3.90^{* * * \# \# \notin \varepsilon \varepsilon}$ \\
\hline
\end{tabular}

All values are expressed mean \pm SEM, $n=6$. Data was analyzed by two-way ANOVA followed by post-hoc Bonferroni multiple comparison test. " $p<0.01$ and "w" $p<0.001$ compared to the respective normal groups. ${ }^{\# \#} p<0.001$ and ${ }^{\# \#} p<0.01$ compared to $1^{\text {st }} \mathrm{w}$ of respective smoking groups (smoking alone and Smoking+T). ${ }^{\text {\&氏 }} \mathrm{p}<0.01$ and ${ }^{\text {\&tat }} \mathrm{p}<0.001$ compared to respective smoking alone groups

$\operatorname{APP}(100 \mathrm{kDa})$

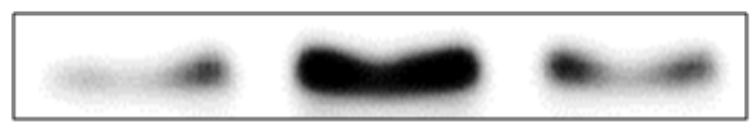

Beta Actin $(42 \mathrm{kDa})$

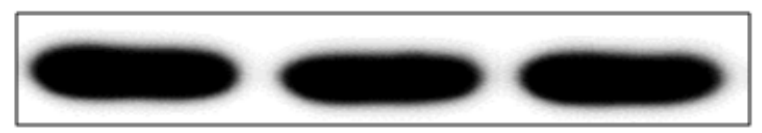

Control

Fig. 1: Blots representing APP expression in hippocampus tissue

Western blot study estimated the bulbar and hippocampal tissue APP expression levels. Chemiluminescence was measured and blots were quantified using ImageJ software 
TABLE 4: EFFECT OF CHRONIC CS EXPOSUREAND CONSTANT BRAIN TRAINING ON HIPPOCAMPAL APP EXPRESSION LEVELS

\begin{tabular}{lc}
\hline Groups & Relative protein expression levels \\
\hline Normal & $0.186 \pm 0.0621$ \\
Smoking alone & $1.035 \pm 0.132^{* *}$ \\
Smoking+T & $0.371 \pm 0.076^{\# \#}$
\end{tabular}

All values are expressed as mean \pm SEM, $n=2$. Data was analysed using one-way ANOVA followed by post-hoc Tukey's multiple comparison test. " $p<0.01$ compared to normal group and ${ }^{\# \#} p<0.01$ compared to smoking alone group

TABLE 5: EFFECT OF BRAIN TRAINING ON HIPPOCAMPAL ROS LEVELS OF CHRONIC SMOKE EXPOSED FEMALE MICE

\begin{tabular}{lc}
\hline Groups & Mean fluorescence intensity \\
\hline Normal & $62.34 \pm 5.66$ \\
Smoking alone & $151.34 \pm 6.70^{* * *}$ \\
Smoking+T & $124.55 \pm 7.80^{* * \#}$ \\
\hline
\end{tabular}

All values are expressed as mean $\pm S E M, n=4$. Data was analysed using one-way ANOVA followed by post-hoc Tukey's multiple comparison test. ${ }^{* * *} p<0.01$ and $" p<0.01$ compared to normal group. ${ }^{\#} p<0.05$ compared to smoking alone group

TABLE 6: EFFECT OF BRAIN TRAINING ON SEROTONIN LEVELS OF SMOKE EXPOSED FEMALE BLACK MICE

\begin{tabular}{lc}
\hline Groups & Serotonin levels $(\mathrm{ng} / \mathrm{mg}$ of wet tissue) \\
\hline Normal & $0.611 \pm 0.045$ \\
Smoking alone & $0.923 \pm 0.068^{* *}$ \\
Smoking+T & $0.854 \pm 0.053^{*}$
\end{tabular}

All values are expressed as mean $\pm S E M, n=4$. Data was analysed using one-way ANOVA followed by post-hoc Tukey's multiple comparison test. " $p<0.01$ and ${ }^{*} p<0.05$ compared to normal group

represented in Table 6. The trained group of animals also exhibited a significant difference in the serotonin levels of hippocampus $(0.854 \pm 0.053 \mathrm{ng} / \mathrm{mg}$ of wet tissue) compared to respective normal tissues (Table 6). However, despite no significant difference between observed between both smoking groups, the serotonin level in Smoking+T group was less than the smoking alone group.

Glutamate contributes to the major excitatory transmissions within the central nervous system (CNS). Increased level of this neurotransmitter is found to toxic to the neuronal cells ${ }^{[29]}$. Glutamate was also estimated by HPLC-EC method. The hippocampal glutamate levels $(1.27 \pm 0.087 \mu \mathrm{g} / \mathrm{mg}$ wet tissue) of smoking alone group increased highly with respect to normal tissue levels $(0.762 \pm 0.087 \mu \mathrm{g} / \mathrm{mg}$ wet tissue) as indicated in Table 7. The trained group of animals exhibited no difference in values compared to the normal group however, their hippocampal glutamate levels $(0.910 \pm 0.064 \mu \mathrm{g} / \mathrm{mg}$ wet tissue) were found to be significantly decreased compared to the smoking alone group.
GABA modulates majority of inhibitory transmissions within the brain. The role of GABA in cognition and its associated diseases has recently been reported. GABA level was estimated by HPLC-EC method through a similar process as that of glutamate measurement. The normal GABA levels of hippocampus were determined to be $0.853 \pm 0.0561 \mu \mathrm{g} / \mathrm{mg}$ wet tissue (Table 7). CS exposure significantly decreased the hippocampal GABA levels compared to normal groups. Smoking alone group expressed GABA levels of 0.321 $\pm 0.0511 \mu \mathrm{g} / \mathrm{mg}$ wet tissue while smoking $+\mathrm{T}$ group expressed $0.445 \pm 0.0352 \mu \mathrm{g} / \mathrm{mg}$ wet tissue of the neurotransmitter, as represented in Table 7. No significant difference was recorded between both the smoke exposed groups. Once again, regardless of the statistical difference, the levels were found to be slightly higher in the smoking $+\mathrm{T}$ hippocampus tissue than smoking alone group.

$\mathrm{AChE}$ is an enzyme which breaks down the major memory associated neurotransmitter, acetylcholine (ACh). Ellman's method was used to measure the AChE levels in hippocampal tissues. The hippocampal AChE levels significantly decreased in the smoking alone group $(19.67 \pm 0.88 \mu \mathrm{M} / \mathrm{min} / \mathrm{mg})$, however, the smoking+T group $(21.88 \pm 0.91 \mu \mathrm{M} / \mathrm{min} / \mathrm{mg})$ showed no significant difference in the enzyme levels in comparison to the normal group $(25.12 \pm 1.05 \mu \mathrm{M} / \mathrm{min} /$ $\mathrm{mg}$ ) as indicated in Table 8.

Cresyl violet staining specifically stains the Nissl's granules and is an indicator of neurodegeneration. Fig. 2 represents the stained hippocampus section of the mice brains (normal and smoke exposed) at different magnifications. Table 9 represents the neuronal count of both the tissues post staining. The normal hippocampus measured a neuronal count of $67.67 \pm 4.47$ neurons $/ 100 \mu \mathrm{m}$. Both the smoke exposed groups also exhibited significant reduction in the hippocampal neuronal count compared to the normal group, smoking alone group expressed $37.21 \pm 4.36$ neurons $/ 100 \mu \mathrm{m}$ while the

TABLE 7: EFFECT OF CONTINUOUS BRAIN TRAINING ON HIPPOCAMPAL GLUTAMATE AND GABA LEVELS POST CS EXPOSURE

\begin{tabular}{lcc}
\hline \multirow{2}{*}{ Groups } & \multicolumn{2}{c}{$\begin{array}{c}\text { Neurotransmitters } \\
(\mu \mathrm{g} / \mathrm{mg} \text { wet tissue })\end{array}$} \\
\cline { 2 - 3 } & Glutamate & GABA \\
\hline Normal & $0.662 \pm 0.087$ & $0.853 \pm 0.05$ \\
Smoking alone & $1.27 \pm 0.087^{* *}$ & $0.321 \pm 0.051^{* * *}$ \\
Smoking+T & $0.795 \pm 0.064^{\#}$ & $0.552 \pm 0.035^{* *}$ \\
\hline
\end{tabular}

All values are expressed as mean $\pm S E M, n=4$. Each data set was analysed using one-way ANOVA followed by post-hoc Tukey's multiple comparison test. ${ }^{* *} p<0.01$ and ${ }^{* *} p<0.001$ compared to normal group. ${ }^{\#} \mathrm{p}<0.05$ compared to smoking alone group 
trained group expressed $45.33 \pm 4.17$ neurons $/ 100 \mu \mathrm{m}$. Neuronal growth was observed in the histopathology sections in both the smoke exposed groups. However, as indicated in the figure and neuronal count, smoking $+\mathrm{T}$ group exhibited a higher neuronal count than smoking alone group, but not statistically significant.

AD contributes maximum to the worldwide dementia statistics. Despite extensive research in the disease pathology, scientists have not been able to decipher the

TABLE 8: EFFECT OF BRAIN TRAINING ON HIPPOCAMPALAChE LEVELS IN SMOKE EXPOSED MICE

\begin{tabular}{lc}
\hline Groups & AChE levels $(\mu \mathrm{M} / \mathrm{min} / \mathrm{mg}$ of protein $)$ \\
\hline Normal & $25.12 \pm 1.05$ \\
Smoking alone & $19.67 \pm 0.88^{*}$ \\
Smoking+T & $21.88 \pm 0.91$
\end{tabular}

All values are expressed as mean $\pm S E M, n=4$. Data was analysed using one-way ANOVA followed by post-hoc Tukey's multiple comparison test. ${ }^{*} p<0.05$ compared to normal group

TABLE 9: EFFECT OF CONTINUOUS BRAIN TRAINING ON HIPPOCAMPAL NEURONAL COUNT POST CIGARETTE SMOKING

\begin{tabular}{lc}
\hline Groups & $\begin{array}{c}\text { Neuronal count (number of } \\
\text { neurons } / 100 \mu \mathrm{m})\end{array}$ \\
\hline Normal & $67.67 \pm 3.47$ \\
Smoking alone & $37.21 \pm 5.36^{* *}$ \\
Smoking+T & $45.33 \pm 3.17^{*}$ \\
\hline
\end{tabular}

All values are expressed as mean $\pm S E M, n=4$. Data was analysed using one-way ANOVA followed by post-hoc Tukey's multiple comparison test. ${ }^{* *} p<0.01{ }^{*} p<0.01$ compared to normal group exact mechanism of the disease formation or progress. Smoking is found to be a major cause of dementia, especially vascular dementia ${ }^{[6]}$. CS is also reported to be an AD causative. Though comparatively less in number, studies have indicated to a beneficial effect of brain stimulation through mental exercises especially in humans. The present study not only provided initial evidence to the possible therapeutic effect of brain training in dementia, but also affirmed the toxic effects of CS exposure on memory.

The cigarette intake of animals was confirmed by estimating cotinine levels in the plasma. The animals exhibited cotinine levels comparable to a human light active smoker. Smoke was found to deleteriously affect the working and retention memory of the animals within a month of exposure as indicated by the first assessment. The animals behaved to be dis-oriented over the course of the study. Constant brain training to the animals using novel object recognition paradigm, significantly recovered the memory functions of CS exposed animals. The mice were found to be better oriented and vigilant than the CS exposed mice.

Cigarette smoking was found to increase the APP levels in hippocampus tissue. APP is a polynucleotide, splitting up of which will generate $A \beta_{1-42}$ through the amyloidogenic pathway. APP antibody used in the study corresponded to the immunogen region of 680 -

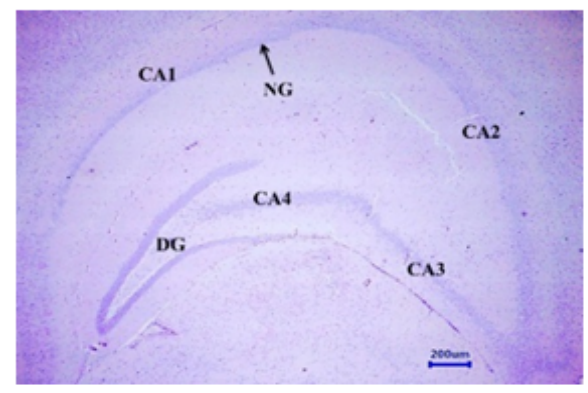

(a)

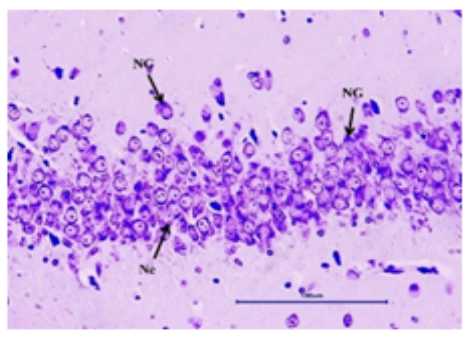

(i)

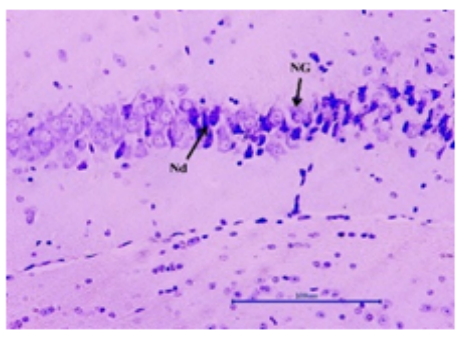

(ii)

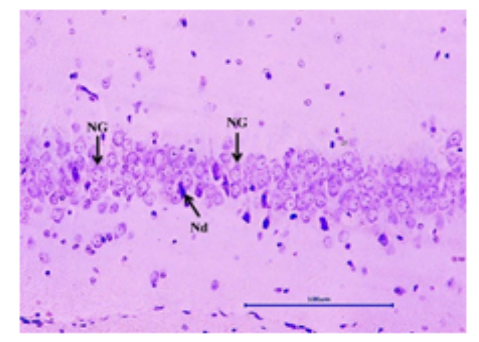

(iii)

Fig. 2: Cresyl violet stained hippocampal sections

Histopathology images (a) Normal Hippocampus (4x); (i) normal hippocampus (40x); (ii) smoking alone hippocampus (40x); (iii) smoking+T hippocampus (40x) 
760 amino acids, associated with the amyloidogenic pathway. Hence was an indicator of $\mathrm{A} \beta_{1-42}$ generation. Additionally, CS is already reported to increase the hippocampal amyloid deposits in $\mathrm{AD}$ mode ${ }^{[10]}$. The increased APP levels could be the result of increased ROS levels in the tissue. ROS contributes heavily to oxidative stress. Many CS constituents like tar, cadmium and lead are reported to be huge generators of ROS and subsequently oxidative stress ${ }^{[30]}$. Oxidative stress is reported to enhance APP production and A $\beta$ deposition in $\mathrm{AD}^{[31]}$. Increased ROS levels in the tissues were responsible for the increased APP expression and the increased APP levels indicated to an increased $A \beta$ generation in both the tissues. Hence, Increased APP levels could be attributed to the memory deficits observed in behavioural assessments. On the contrary, brain training was found to decrease ROS levels and almost normalise the APP expression in hippocampus, both of which could contribute to better memory functions as indicated by previous scientific evidences and our obtained data.

$\mathrm{AChE}$ levels are an indirect measure of the memory specific neurotransmitter, ACh. The enzyme is responsible for the breakdown of ACh. AChE level was found to be decreased upon CS exposure; no difference was observed in both groups. Decreased AChE activity could be due to the cholinomimetic effects of nicotine, major constituent of tobacco. The major excitatory neurotransmitter, glutamate, was found to be significantly increased in the tissue post smoke exposure. This excitotoxic effect of CS could also be a result of increased brain nicotine levels. Nicotine has been reported to elevate brain glutamate levels thereby increasing the dopamine neurotransmitter levels, responsible for the pleasurable effects of $\mathrm{CS}^{[32]}$. Cigarette smoking was also found to increase the drebrin expression, dendritic spine protein primarily receiving excitatory inputs ${ }^{[33]}$. Contradicting the glutamate levels, GABA, the major inhibitory neurotransmitter was found to significantly decrease in the hippocampal tissue but however did not exhibit any change in the bulbar GABA levels. The decrease in GABA could also be attributed to the increased nicotine activity. As discussed, nicotine requires dopamine to produce its pleasurable effects. To maintain this effect of dopamine, nicotine prevents GABA signalling as increased GABA reduces dopamine release from the substantia nigra pars compacta ${ }^{[32]}$. Brain training was found to decrease the glutamate levels compared to smoking alone group. The decreased excitatory neurotransmitter level could probably be due to the decreased ROS levels and APP levels eventually leading to toxic $A \beta$ formation. $A \beta$ peptides are reported to increase the glutamate levels and subsequently trigger neuronal cell death. Again, decreased $A C h E$ levels also could have served beneficial since AChE-A $\beta$ complex have also been reported to cause calcium overload in neuronal population.

Serotonin, the mood regulating neurotransmitter, has been reported for its memory benefitting effects. CS exposure was found to increase the serotonin levels in the hippocampus tissue. Increased serotonin levels could be attributed to the monoamine oxidase $\mathrm{A}$ and $\mathrm{B}$ inhibitory activity of 2,3,6-trimethyl-benzoquinone and 2-naphthylamine, major components in $\mathrm{CS}^{[34]}$. Brain training group did not exhibit any significant difference in the serotonin levels. Additionally, neuronal degeneration in both tissues was measured using cresyl violet staining for substantiating the observed effects. CS exposure was found to significantly increase hippocampal neurodegeneration owing to the increased APP expression and ROS levels in the tissues. The images in fig. 2 clearly indicated to the decreased neuronal count compared to the normal tissue. Interestingly, the neuronal count was to better post continuous brain training than the smoking alone group. Neuronal growth was indicated prominently. However, even the hippocampal neurons from trained group portrayed neurodegeneration despite the beneficial effects indicated in memory functions.

Our study was able to provide initial evidences for the positive effects of brain training on memory. Brain training not only had a significant effect on behavioural functions of the CS exposed animals but also could decrease the levels of APP encoding for amyloidogenic pathway, which otherwise markedly increased in the hippocampus tissue of the smoking alone group of animals. Hence, we could successfully gather evidences on the mitigating effects of continuous brain training on CS induced dementia and additionally, confirm the detrimental effects of CS on memory via studying for amyloid genesis, excitotoxicity and neurodegeneration; all of them serving as primary data for mechanistic studies associated to each pathway.

The favourable effects of brain training on memory could serve as another supporting scientific evidence for CST since the therapy basically involves constant brain stimulation through mental exercises. Further detailed experimental studies of continuous cognitive stimulations in rodent models specifically for $\mathrm{AD}$ could ascertain the therapeutic efficacy of the non- 
pharmacological therapy in dementias leading to chronic neurodegenerative diseases. These data could eventually pave paths to a safe yet effective treatment strategy, not compromising the quality of life of the patients. Moreover, the neurotoxic effect of CS was confirmed once again with histopathology data to substantiate the neurodegeneration induced in the process. However, further detailed mechanistic studies are significant to delineate the major pathway, precisely inflammatory pathway, involved in CS induced AD.

\section{Acknowledgements:}

The authors are thankful to Department of Science and Technology, Government of India for providing fellowship to Ms. Anjali Raj and financially aiding the work. The authors are also thankful to JSS Academy of Higher education \& Research for providing the necessary infrastructure to perform experiments related to the study.

\section{Conflicts of interest:}

The authors declared no conflict of interest.

\section{REFERENCES}

1. Sadigh-Eteghad S, Sabermarouf B, Majdi A, Talebi M, Farhoudi M, Mahmoudi J. Amyloid-beta: a crucial factor in Alzheimer's disease. Med Princ Pract 2015;24(1):1-10.

2. Klafki HW, Staufenbiel M, Kornhuber J, Wiltfang J. Therapeutic approaches to Alzheimer's disease. Brain 2006;129(11):2840-55.

3. Wu N, Rao X, Gao Y, Wang J, Xu F. Amyloid- $\beta$ deposition and olfactory dysfunction in an Alzheimer's disease model. J Alzheimers Dis 2013;37(4):699-712.

4. World Alzheimer Report 2015: The global impact of dementia: An analysis of prevalence, incidence, cost and trends. Alzheimer's Disease International, UK; 2015.

5. World Alzheimer Report 2018: The state of the art of dementia research: New frontiers. Alzheimer's Disease International, $\mathrm{UK} ; 2018$.

6. Bernhard D, Moser C, Backovic A, Wick G. Cigarette smokean aging accelerator? Exp Gerontol 2007;42(3):160-5.

7. Durazzo TC, Meyerhoff DJ, Nixon SJ. Chronic cigarette smoking: implications for neurocognition and brain neurobiology. Int J Environ Res Public Health 2010;7(10):376091.

8. Brody AL, Mandelkern MA, Jarvik ME, Lee GS, Smith EC, Huang JC, Bota RG, Bartzokis G, London ED. Differences between smokers and nonsmokers in regional gray matter volumes and densities. Biol Psychiatry 2004;55(1):77-84.

9. Kalmijn S, Van Boxtel MP, Verschuren MW, Jolles J, Launer LJ. Cigarette smoking and alcohol consumption in relation to cognitive performance in middle age. Am J Epidemiol 2002;156(10):936-44.

10. Moreno-Gonzalez I, Estrada LD, Sanchez-Mejias E, Soto C. Smoking exacerbates amyloid pathology in a mouse model of Alzheimer's disease. Nat Commun 2013;4(1):1-10.
11. Paddock C. Smoking may not be related to dementia risk after all. Healthline Media; 2019.

12. Kim K, Han JW, So Y, Seo J, Kim YJ, Park JH, et al. Cognitive stimulation as a therapeutic modality for dementia: A metaanalysis. Psychiatry Investig 2017;14(5):626-39.

13. Ali A, Brown E, Spector A, Aguirre E, Hassiotis A. Individual cognitive stimulation therapy for people with intellectual disability and dementia: protocol of a feasibility randomised controlled trial. BMJ open 2018;8(12):e022136.

14. Fratiglioni L, Wang HX. Brain reserve hypothesis in dementia. J Alzheimers Dis 2007;12(1):11-22.

15. Bennett DA, Wilson RS, Schneider JA, Evans DA, De Leon $\mathrm{CM}$, Arnold SE, et al. Education modifies the relation of AD pathology to level of cognitive function in older persons. Neurology 2003;60(12):1909-15.

16. Hitchman SC, Fong GT. Gender empowerment and femaleto-male smoking prevalence ratios. Bull World Health Organ 2011;89:195-202.

17. Lueptow LM. Novel object recognition test for the investigation of learning and memory in mice. J Vis Exp 2017;(126):e55718.

18. Quillfeldt, JA, Alberto J. Behavioral methods to study learning and memory in rats. In: Andersen, Monica Levy, Tufik, Sergio editors. Rodent model as tools in ethical biomedical research. USA: Springer International Publishing; 2016. p. 271-311.

19. Kameyama T, Nabeshima T, Kozawa T. Step-down-type passive avoidance-and escape-learning method: Suitability for experimental amnesia models. J Pharmacol Methods 1986;16(1):39-52.

20. Ali T, Yoon GH, Shah SA, Lee HY, Kim MO. Osmotin attenuates amyloid beta-induced memory impairment, tau phosphorylation and neurodegeneration in the mouse hippocampus. Sci Rep 2015;5(1):1-7.

21. Tang J, Yuan Y, Wei C, Liao X, Yuan J, Nanberg E, et al. Neurobehavioral changes induced by di (2-ethylhexyl) phthalate and the protective effects of vitamin E in Kunming mice. Toxicol Res 2015;4(4):1006-15.

22. Maheswari DU, Anand T, Manu TM, Khanum F, Sharma RK. Motion sickness induces physiological and neuronal alterations in a mouse model. Int J Pharm Sci Res 2019;10:1650-9.

23. Monge-Acuna AA, Fornaguera-Trias J. A high performance liquid chromatography method with electrochemical detection of gamma-aminobutyric acid, glutamate and glutamine in rat brain homogenates. J Neurosci Methods 2009;183(2):176-81.

24. Paul R, Borah A. Global loss of acetylcholinesterase activity with mitochondrial complexes inhibition and inflammation in brain of hypercholesterolemic mice. Sci Rep 2017;7(1):1-3.

25. Wang Y, Wang B, Zhu MT, Li M, Wang HJ, Wang M, et al. Microglial activation, recruitment and phagocytosis as linked phenomena in ferric oxide nanoparticle exposure. Toxicol Lett 2011;205(1):26-37.

26. Galeazzi RL, Daenens P, Gugger M. Steady-state concentration of cotinine as a measure of nicotine-intake by smokers. Eur J Clin Pharmacol 1985;28(3):301-4.

27. Hardy J, Selkoe DJ. The amyloid hypothesis of Alzheimer's disease: progress and problems on the road to therapeutics. Science 2002;297:353-6.

28. Aboukhatwa M, Dosanjh L, Luo Y. Antidepressants are a rational complementary therapy for the treatment of Alzheimer's disease. Mol Neurodegener 2010;5(1):1-7.

29. Morrison AS, Lyketsos C. The pathophysiology of Alzheimer's disease and directions in treatment. Adv Stud Nurs 2005;3(8):256-70.

30. Ueha R, Ueha S, Kondo K, Kikuta S, Yamasoba T. Cigarette 
smoke-induced cell death causes persistent olfactory dysfunction in aged mice. Front Aging Neurosci 2018;10:183.

31. Dong S, Duan Y, Hu Y, Zhao Z. Advances in the pathogenesis of Alzheimer's disease: a re-evaluation of amyloid cascade hypothesis. Transl Neurodegener 2012;1(1):1-2.

32. The science of nicotine addiction. National institutes of health, Department of Health and Human Services, Scholastic and the
Scientists of the National Institute on Drug Abuse; 2007.

33. Ho YS, Yang X, Yeung SC, Chiu K, Lau CF, Tsang AW, et al. Cigarette smoking accelerated brain aging and induced preAlzheimer-like neuropathology in rats. PLoS One 2012 May 11;7(5):e36752.

34. Fowler JS, Logan J, Wang GJ, Volkow ND. Monoamine oxidase and cigarette smoking. Neurotoxicology 2003;24(1):75-82. 